\title{
Dermatitis de contacto alérgica e irritativa en región vulvar. Impacto de los jabones íntimos
}

Allergic and irritative contact dermatitis in vulvar region. Impact of intimate soaps

\section{Adriana Patricia Cruz', Sonia Salamanca², Natalia Hernández³ Johanna Alexandra Villamil$^{4}$, Diana Carolina Quiasua ${ }^{5}$}

1. Dermatóloga, Universidad Nacional de Colombia

2. Ginecóloga, Universidad Javeriana

3. Dermatóloga, Universidad Militar

4. Médica General, Universidad El Bosque

5. Médica General, Universidad El Rosario

\section{RESUMEN}

La dermatitis de contacto vulvar es un problema común en dermatología y ginecología; afecta de manera importante la salud y la calidad de vida de las mujeres que la padecen. Más del 50\% de los casos de prurito vulvar crónico en mujeres adultas puede ser atribuido a sustancias irritantes y alérgenos ${ }^{(1)}$, entre ellos los denominados jabones íntimos, cuyo uso es cada vez más frecuente. El principal síntoma de la dermatitis es irritación en la región vulvar; puede presentar síntomas como prurito, ardor y dolor. La dermatitis de contacto se produce después de la exposición a irritantes exógenos o alérgenos. Clínicamente son difíciles de diferenciar estas dos entidades; se requiere realizar una adecuada historia clínica, que indague sobre posibles alérgenos, realizar un examen físico completo y una prueba de parche, único método diagnóstico que confirma la dermatitis alérgica por contacto ${ }^{(2)}$, para realizar un diagnóstico acertado e iniciar un tratamiento adecuado y eliminar el factor desencadenante.

PALABRAS CLAVE: dermatitis de contacto, eccema, vulva, jabones, pruebas del parche.

\section{SUMMARY}

Vulvar contact dermatitis is a common problem in dermatology and gynecology. It affects the health and life quality of women with this disease in a significant way. Over $50 \%$ of cases of chronic vulvar pruritus in adult women can be attributed to irritative or allergic substances ${ }^{(1)}$, including the use of all those soaps self-referenced as intimate soaps, which is becoming increasingly frequent. The main symptom is irritation in the vulvar region; it can present related symptoms such as itching, burning and pain. Contact dermatitis occurs after exposure to exogenous irritants or allergens. Clinically, both of these states are difficult to differentiate; an adequate clinical history is required to investigate possible allergens, along with a complete physical examination and patch test being the only diagnostic method that confirms allergic contact dermatitis ${ }^{(2)}$ in order to have an accurate diagnosis, initiate appropriate treatment and eliminate the triggering factor.

KEY WORDS: Dermatitis Allergic Contact, Eczema, Vulva, Soaps, Patch Tests
Correspondencia:

Adriana Patricia Cruz Garnica

Email:

adripcruz@gmail.com

Recibido: $30 / 03 / 18$

Aceptado: 26/02/19

Conflictos de interés:

No se reportan conflictos de interés.

Financiación:

Ninguna. 


\section{INTRODUCCIÓN}

Las dermatitis de la región vulvar suelen manifestarse generalmente con prurito o ardor. Es muy frecuente que, en la práctica clínica, las dermatitis se confundan con infecciones, especialmente fúngicas, o que al examen físico puedan tener cambio en su expresión clínica por el uso de medicamentos como corticoides, por lo que el diagnóstico y el tratamiento correcto se retrasan durante meses ${ }^{(3)}$. Su aparición simultánea en otra área del cuerpo puede facilitar el diagnóstico (ya que a veces la morfología clínica de diferentes dermatitis en el área vulvar es difícil de distinguir); sin embargo, en muchas oportunidades se presenta con compromiso único.

\section{ANATOMÍA DE LA REGIÓN VULVAR}

Los órganos genitales externos están constituidos por el monte de venus, los labios mayores, los labios menores, el clítoris y las estructuras glandulares (figura 1). El tamaño y la forma de estas estructuras, su pigmentación y la distribución del pelo muestran una variación considerable dependiente del estado hormonal, la estructura pélvica, la raza y la edad (figura 1) (4).

La vulva son los genitales externos femeninos, que se encuentran dentro del triángulo perineal anterior, que abarca desde el pubis en el monte de venus al cuerpo

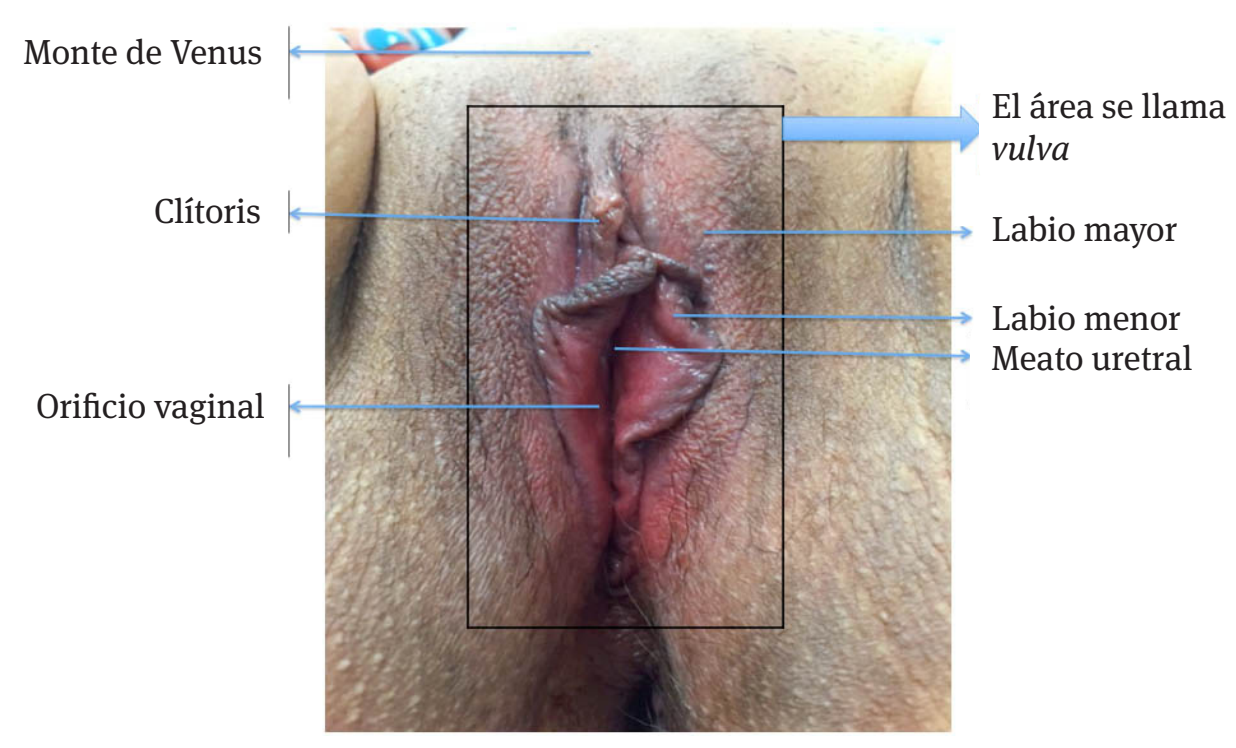

Figura 1. Anatomía de las estructuras vulvares.

perineal posterior y lateralmente desde el pliegue in guinal al anillo himeneal. La vulva está compuesta por los labios mayores y menores, el capuchón del clítoris, el meato urinario, el introito vaginal y las glándulas vestibulares mayores (de Bartholino) y menores (de Skene) (5).

La vulva se encuentra tapizada por dos tipos de epitelios: los labios mayores y la cara externa de los labios menores hasta la línea de Hart, que están cubiertos por epitelio escamoso estratificado queratinizado, mien- tras que el vestíbulo vulvar está revestido por epitelio transicional no queratinizado, que se asemeja morfológicamente a la mucosa vaginal ${ }^{(5)}$.

Comparada con otras áreas, la piel vulvar está expuesta a muchos más irritantes fisiológicos de contacto, como el sudor, las secreciones vaginales, la orina, la oclusión por ropa interior, las toallas y los protectores sanitarios, el contacto piel a piel y el trauma mecánico por roce con la ropa, actividad sexual, entre otros. Debido a que la vulva está casi siempre cubierta de alguna ma- 
nera, el grado de oclusión es un factor único que debe considerarse, y los efectos pueden ser significativos ${ }^{(3)}$.

Una consecuencia puede ser la hidratación aumentada de la piel, como lo demuestran las elevadas medidas en la pérdida de agua transepidérmica (TEWL, por sus siglas en inglés); esto aumenta el coeficiente de fricción de la piel vulvar, lo cual predispone a daños mecánicos. Los valores elevados de TEWL sugieren que la piel vulvar no es tan eficaz como barrera a la pérdida de agua como otras áreas de la piel ${ }^{(6)}$. Esta medida también está relacionada con la permeabilidad, que es hasta siete veces más alta en la piel vulvar que en la piel del antebrazo ${ }^{(7)}$.

En cuanto a los factores contribuyentes, se incluyen una mayor concentración de glándulas sudoríparas y folículos pilosos, aumento del flujo sanguíneo cutáneo y mayor hidratación. Similar a la mucosa bucal, la permeabilidad está particularmente elevada en el vestíbulo vulvar no queratinizado, porque el estrato córneo ausente disminuye la función de barrera y también la distancia necesaria para que una sustancia exógena se desplace ${ }^{(8)}$. Así, la piel vulvar es muy sensible a los agentes tópicos ${ }^{(9)}$.

Otra característica única del epitelio vulvar es su capacidad de respuesta hormonal, particularmente a los estrógenos. El estrato córneo de los labios mayores gradualmente se espesa con la edad hasta la menopausia, momento en el que los niveles de estrógeno en circu- lación disminuyen. Esto conduce a la atrofia de los tejidos y disminución de la elasticidad, lo que perjudica la capacidad de la piel para actuar como una barrera a las exposiciones externas ${ }^{(10)}$. La degeneración elástica observada en la dermis vulvar posmenopáusica es comparable a la que se observa con años de exposición solar y daño actínico en la población geriátrica. La disminución del estrógeno aumenta adicionalmente el pH típicamente ácido del área y disminuye la producción de lípidos (dos factores que normalmente contribuyen a la función protectora de la piel). Como resultado de estos cambios, los tejidos vulvares y vaginales se vuelven cada vez más sensibles en la población posmenopáusica $^{(11)}$.

\section{DERMATITIS DE CONTACTO}

La dermatitis de contacto es un diagnóstico común, con tasas de prevalencia reportadas de hasta el 54\% para las pacientes que consultan en las clínicas vulvares ${ }^{(12)}$. Ocurre después de la exposición a irritantes exógenos (dermatitis de contacto irritativa) o alérgenos (dermatitis alérgica de contacto), y puede presentarse en sus formas aguda, subaguda o crónica. En su forma aguda, puede ser extremadamente dolorosa, con erosiones asociadas y lesiones ampollosas (figura 2); en la subaguda, se evidencia eritema y áreas de descamación (figura 3); y en la forma crónica, se evidencia placa gruesa y liquenificada con excoriaciones (figura 4) ${ }^{(9)}$.

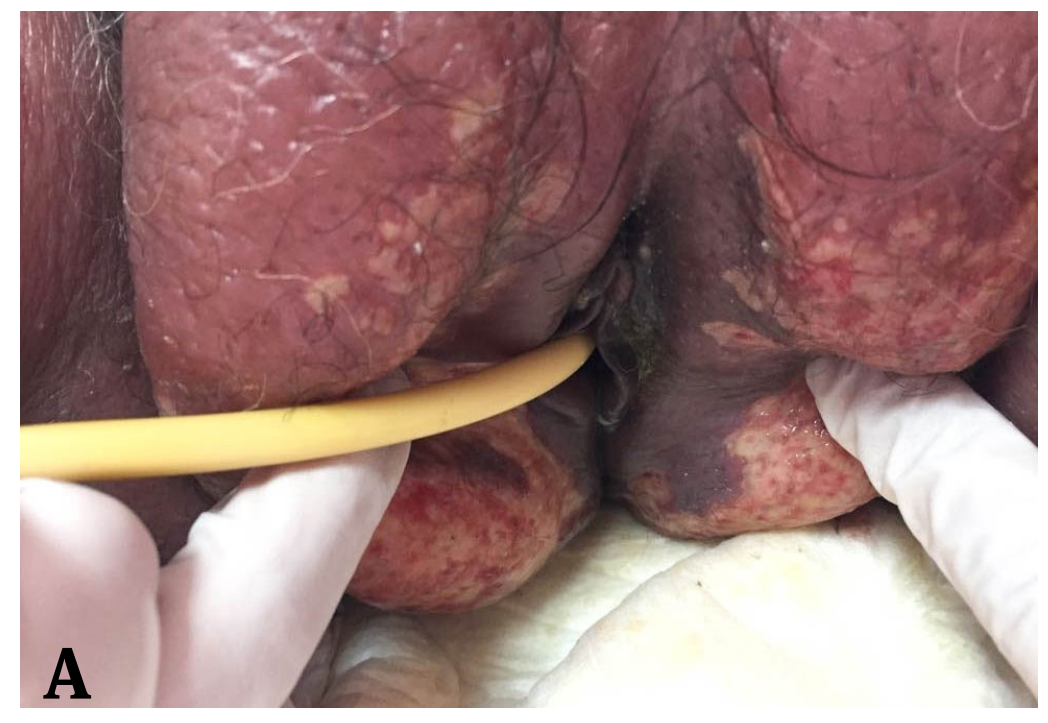




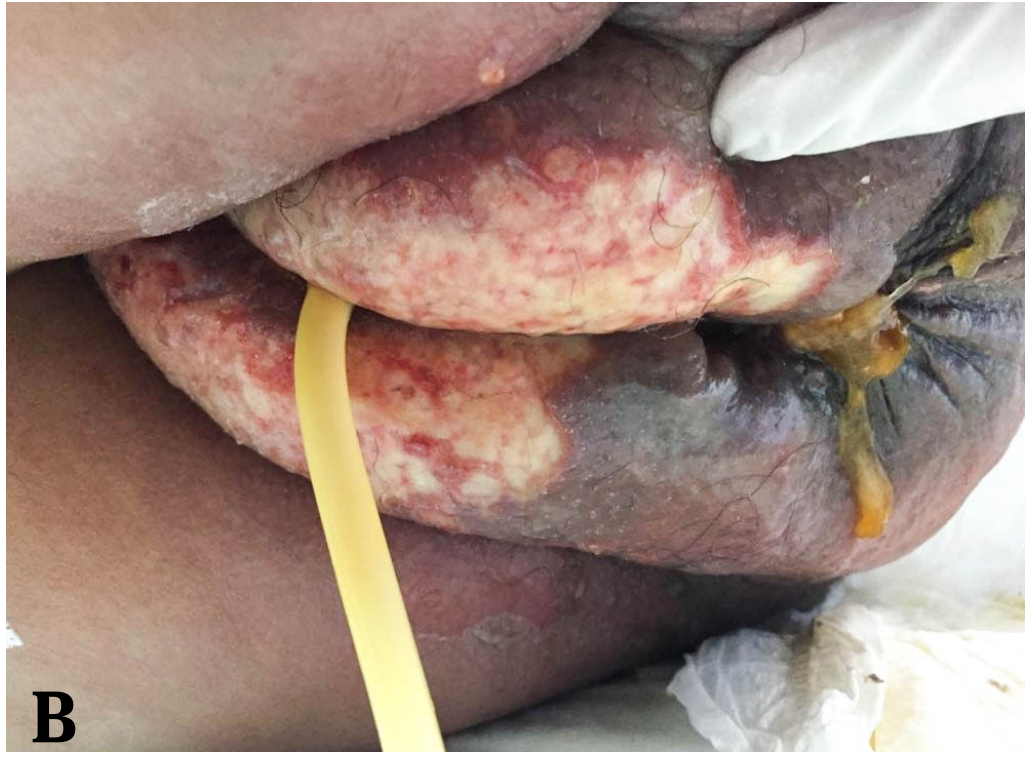

Figura 2 A y B). Paciente con dermatitis contacto aguda secundaria a uso de isodine jabón durante procedimiento quirúrgico.

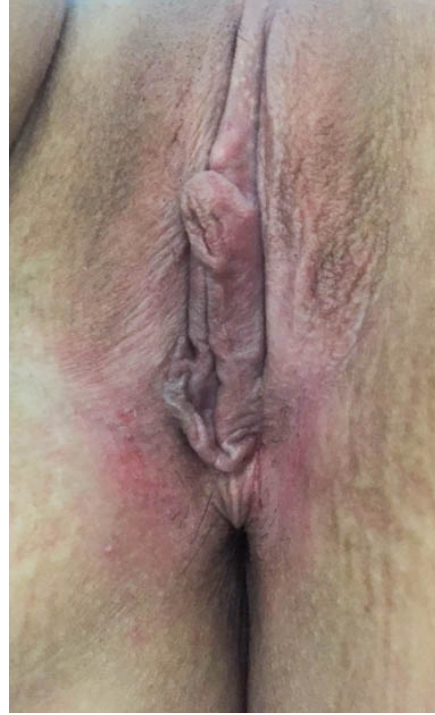

Figura 3. Dermatitis subaguda.

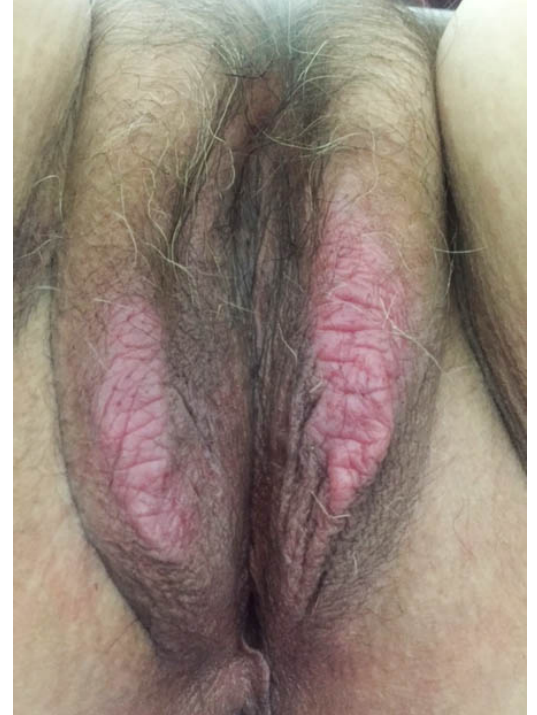

Figura 4. Paciente con dermatitis de contacto crónica y liquen simple. Observe las placas eritematosas de bordes bien definidos en los labios mayores, color rosada, con aumento del reticulado, engrosada. 


\section{DERMATITIS DE CONTACTO IRRITATIVA}

La dermatitis de contacto irritativa es la forma más común de dermatitis de contacto ${ }^{(13)}$. Esta se produce después de la exposición a sustancias que tienen efectos citotóxicos directos sobre los queratinocitos, y como tal, no requiere sensibilización previa. Estos efectos pueden incluir daño a las membranas celulares, desnaturalización de la queratina y otras proteínas, y eliminación de los lípidos superficiales y sustancias hidrofílicas ${ }^{(14)}$. Después de la irritación puede ocurrir sensibilización secundaria ${ }^{(15)}$.

Los síntomas más comunes de la dermatitis de contacto son irritación y prurito. Su severidad y rapidez de inicio se determinan por la potencia del agente ofensor y la duración o cronicidad de la exposición. Debido a que la vulva está generalmente bien protegida con la ropa, el contacto con irritantes fuertes es mucho menos común, la cual podría suceder en pacientes con déficit sensorial $^{(9)}$.

Además de la variabilidad individual en la sensibilidad de la piel, existen otros factores para aumentar el riesgo de dermatitis. Los factores etiológicos en la dermatitis irritativa vulvar son múltiples y se clasifican como endógenos o exógenos (tabla 1). La obesidad conduce a una mayor oclusión, lo que produce aumento en la humedad y, por tanto, aumenta la fricción, que favorece un daño mecánico; este es considerado un factor endógeno ${ }^{(6)}$. Otro factor propio puede ser la incontinencia urinaria, que produce aumento en la humedad de la piel, pero que también causa irritación por la orina y el amoníaco ${ }^{(9)}$. Los pacientes con dermatitis atópica, Sjögren, hipotiroidismo y psoriasis de localización genital pueden presentar una mayor tendencia a la irritación.

Tabla 1. Sustancias irritativas

\begin{tabular}{|c|c|}
\hline Factores exógenos & Factores endógenos \\
\hline Desodorantes higiénicos/aerosol de higiene & Amoniaco de la orina-humedad \\
\hline Geles de ducha/jabones íntimos & Obesidad-oclusión-humedad \\
\hline $\begin{array}{l}\text { Medicamentos tópicos: antifúngicos, antibióticos, } \\
\text { antisépticos, anestésicos, esteroides, ácido } \\
\text { tricloroacético, derivados de alcoholes, fluorouracilo y } \\
\text { propilenglicol }\end{array}$ & $\begin{array}{l}\text { Incontinencia fecal (enzima pancreatina, que } \\
\text { contiene lipasa, proteasa y amilasa) }\end{array}$ \\
\hline Remedios caseros & Descarga vaginal \\
\hline $\begin{array}{l}\text { Toallas íntimas, tampones, almohadillas menstruales } \\
\text { y de incontinencia }\end{array}$ & Sudor \\
\hline \multicolumn{2}{|l|}{ Espermicidas/lubricantes/látex condón y semen } \\
\hline \multicolumn{2}{|l|}{ Duchas vaginales } \\
\hline \multicolumn{2}{|l|}{ Hidrocarburos fluorados (productos de higiene) } \\
\hline \multicolumn{2}{|l|}{ Detergentes, suavizante de ropa, blanqueador } \\
\hline $\begin{array}{l}\text { Ropa ajustada, nylon, látex, esponjas de ducha, agua } \\
\text { caliente, lavado excesivo, secado vigoroso con toalla, } \\
\text { secador de pelo (aire caliente) }\end{array}$ & \\
\hline
\end{tabular}

Modificada de la referencia 8. 
Los factores exógenos son los múltiples irritantes que pueden entrar en contacto con la piel vulvar. Los irritantes vulvares más frecuentes se describen en la tabla 2. De acuerdo con el estudio de de-Groot ${ }^{(16)}$, la mayoría de las reacciones adversas a los cosméticos fueron causadas por productos para el cuidado de la piel (36,6\%), seguidos por productos de limpieza personal (29,5\%), desodorantes y antitranspirantes (12,6\%).

Tabla 2. Alérgenos vulvares

\begin{tabular}{|c|c|}
\hline Antibióticos & Neomicina, bacitran, sulfonamidas, polimixina \\
\hline Antimicóticos & Imidazoles (itraconazol, miconazol, clotrimazol), nistatina, nifuratel \\
\hline Antiherpéticos & Aciclovir \\
\hline Antisépticos & $\begin{array}{l}\text { Clorhexidina, violeta de genciana, sales fenil mercúricas, povidona yodada, } \\
\text { timerosal }\end{array}$ \\
\hline Anestésicos & $\begin{array}{l}\text { Ésteres (benzocaína, tetracaína, procaína), amidas (lidocaína, dibucaína, } \\
\text { bupivacaína, mepivacaína), crotamitón, difenhidramina }\end{array}$ \\
\hline AINE & Bufexamac \\
\hline Emolientes & Lanolina, aceite de jojoba, glicerina, glicol propileno \\
\hline Corticosteroides & $\begin{array}{l}\text { Hidrocortisona, metilprednisolona, fludrocortisona, prednisolona, budesonida, } \\
\text { triamcinolona, betametasona, dexametasona, clobetasol, fluticasona, mometasona }\end{array}$ \\
\hline Fragancias & $\begin{array}{l}\text { Bálsamo de Perú, alcohol cinámico, aldehído cinámico, hidroxi citronella, eugenol, } \\
\text { isoeugenol }\end{array}$ \\
\hline Quitaesmaltes & Tolueno, sulfonamida, resina de formaldehído \\
\hline Preservativos & $\begin{array}{l}\text { Alcohol estearil formaldehído, liberadores de formaldehído (quaternium 15, } \\
\text { imidazolidinilurea, diazolidinilurea), bronopol }\end{array}$ \\
\hline Toallas higiénicas & Acetil acetona, fragancia, metacrilatos, formaldehído \\
\hline Duchas & $\begin{array}{l}\text { Fragancia, aceite de eucalipto, timol, oxiquinolina, metil salicilato, acetato } \\
\text { fenilmercurio, cloruro de bencetonio }\end{array}$ \\
\hline Metales & Níquel, paladio, oro \\
\hline Espermicidas & $\begin{array}{l}\text { Quinina, clorhidrato de quinina, sulfato de oxoquinolina nonoxinol, butirato de fenil } \\
\text { mercurio, acetato de fenil mercurio, hexilresorcinol }\end{array}$ \\
\hline Caucho & Diafragma, condón, guantes: látex, tiuram, mercaptobenzotiazol \\
\hline Plantas & $\begin{array}{l}\text { Veneno, hiedra, zumaque, roble: urushiol; mazanilla, tintura de Arnica montana, } \\
\text { propóleo }\end{array}$ \\
\hline Fluidos corporales & Semen, saliva \\
\hline Colorantes textiles & $\begin{array}{l}\text { Disperse Orange } 3 \text { (colorante azo), Disperse Blue } 35 \text { y } 153 \text { (colorante de } \\
\text { antraquinona) }\end{array}$ \\
\hline
\end{tabular}

AINE: antiinflamatorios no esteroideos. 
Las duchas y los jabones íntimos contienen irritantes y sensibilizadores. Los principales irritantes en las duchas son el alumbre, el ácido cítrico y el ácido láctico. El bicarbonato de sodio y el borato de sodio son álcalis que causan reacciones irritativas de contacto ${ }^{(17)}$.

El laurilsulfato de sodio (SLS) es un detergente aniónico y tensoactivo utilizado como agente espumante en muchos jabones y champús. Este componente también se encuentra en la gran mayoría de los jabones denominados como "íntimos" y ha sido implicado como desencadenante de la dermatitis de contacto irritativa de la región vulvar; se ha postulado que contribuye a la hiperalgesia induciendo citocinas proinflamatorias (tabla 3) ${ }^{(18)}$.

Tabla 3. Tipos de surfactantes

\begin{tabular}{|c|c|c|}
\hline Tipo de surfactante & Compuesto químico & Usos-propiedades \\
\hline \multirow{5}{*}{ Aniónicos } & $\begin{array}{l}\text { Lauril sulfato de sodio } \\
\text { Laureth sulfato de sodio }\end{array}$ & $\begin{array}{l}\text { Detergente, humectante, } \\
\text { solubilizante, agente emulsionante }\end{array}$ \\
\hline & Mireth sulfato de sodio & Tienen alto potencial irritante \\
\hline & Coco sulfato de sodio & \\
\hline & Tricedeth sulfato de sodio & \\
\hline & Laureth sulfato de magnesio & \\
\hline \multirow{16}{*}{ Catiónico } & $\begin{array}{l}\text { Policuaternario } 10 \\
\text { Policuaternario } 7\end{array}$ & $\begin{array}{l}\text { Agente acondicionador de pelo } \\
\text { (suavizante), agente } \\
\text { antimicrobiano, conservante }\end{array}$ \\
\hline & Diazolidinilurea & \multirow{15}{*}{$\begin{array}{l}\text { Alto potencial irritante y son más } \\
\text { citotóxicos que los aniónicos }\end{array}$} \\
\hline & Ácido dehidroacético & \\
\hline & Imidazolidinilurea & \\
\hline & Centaurea cyanus & \\
\hline & Metilisotiazolinona & \\
\hline & Hidantoína & \\
\hline & Lactato de potasio & \\
\hline & Yodo propinil butil carbamato & \\
\hline & Metil parabeno & \\
\hline & Fenoxietanol & \\
\hline & Benzoato de sodio & \\
\hline & Propil parabeno & \\
\hline & Triclosán & \\
\hline & Cloruro de benzalconio & \\
\hline & Cetrimida & \\
\hline
\end{tabular}




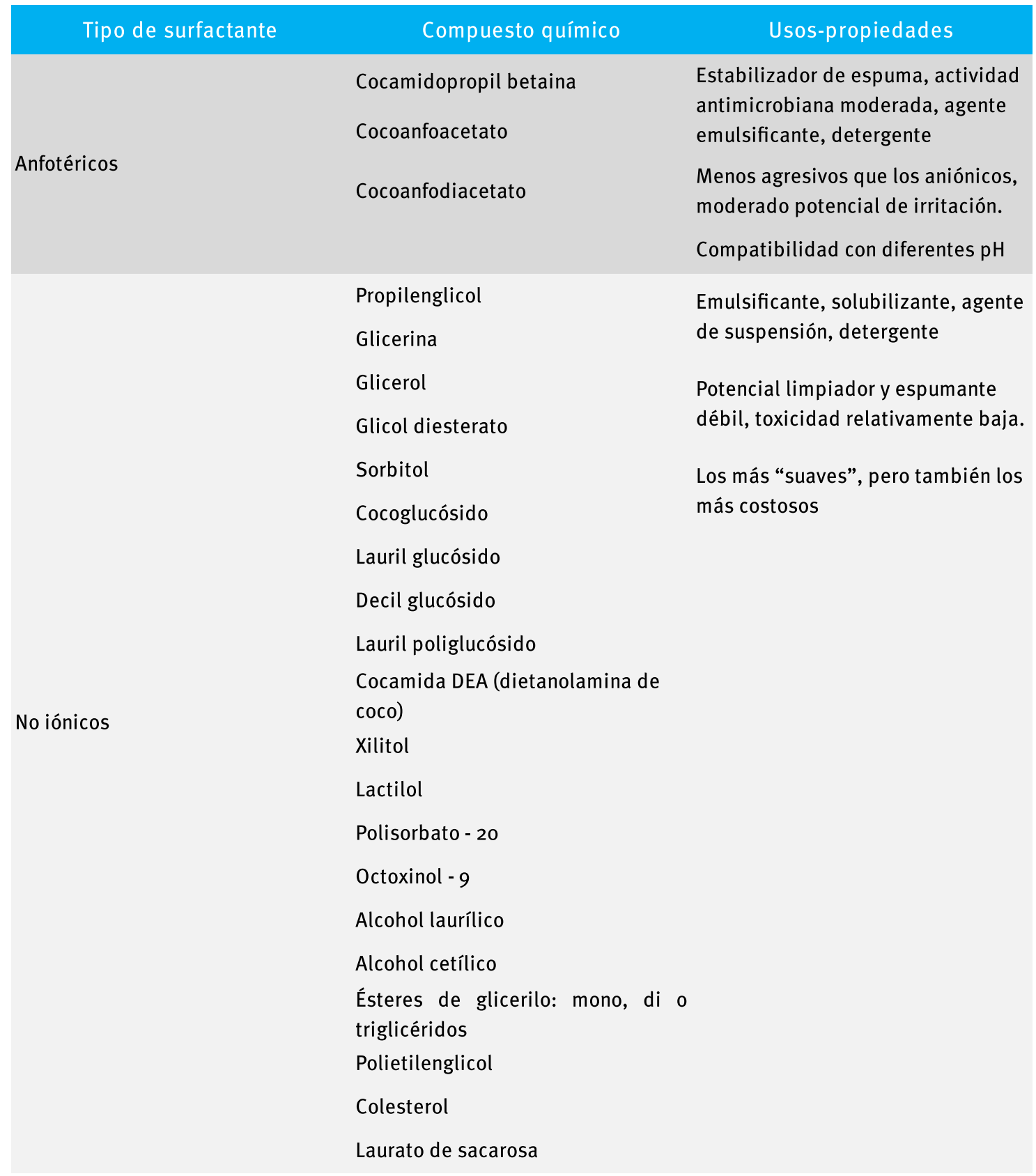

\section{DERMATITIS ALÉRGICA DE CONTACTO}

La dermatitis alérgica de contacto es una reacción de hipersensibilidad de tipo IV o retardada, que compromete las células dendríticas, las cuales captan y procesan los antígenos y luego migran a los ganglios linfáticos para presentarlos a los linfocitos T. La presentación antigénica y el ambiente de citocinas, induce la diferenciación y proliferación de células $\mathrm{T}$ y la producción subsiguiente de citocinas inflamatorias. Las células T migran nuevamente a la piel para dar lugar a la respuesta inflamatoria, al mismo tiempo se generan células $\mathrm{T}$ de memoria, responsables de las manifestaciones clínicas ante la reexposición a los alérgenos. Las manifestaciones clínicas pueden tardar de 48 a 72 horas en aparecer después de la exposición, por lo que el alérgeno suele ser difícil de identificar ${ }^{(9)}$. Los signos clínicos son similares en cualquier tipo de dermatitis. 
La lista de alérgenos es aún más larga que la de los irritantes, lo que hace que la tarea de identificar al agente responsable sea aún más difícil. En la tabla 2 se encontrarán los diferentes alérgenos más comunes causantes de la dermatitis alérgica de contacto. Al igual que con los irritantes, los alérgenos se pueden encontrar en jabones, detergentes, toallitas y cremas ${ }^{(13)}$.

Cuando un paciente presenta una reacción a un medicamento tópico, puede que no sea secundario al agente activo, sino a los preservantes o vehículo del medicamento. Entre ellos encontramos los parabenos, los estabilizadores, las etilendiaminas, las fragancias como el bálsamo de Perú, entre otros ${ }^{(19)}$.

El bálsamo de Perú es un compuesto natural de acetato de bencilo, alcohol bencílico, ácido cinámico, considerado un marcador útil para la alergia a las fragancias, con una reacción de parche positiva en más del 50\% de los pacientes alérgicos a las fragancias ${ }^{(20)}$. Puede encontrarse en cremas y jabones perfumados.

Los alérgenos más importantes en los medicamentos tópicos y remedios caseros fueron ingredientes activos como anestésicos locales (los cuales sensibilizaban con mayor frecuencia), antibióticos, antimicóticos tópicos, antiinflamatorios no esteroideos (AINE), corticosteroides, antiherpéticos tópicos, extractos de hierbas, baños caseros, preparaciones cosméticas (manzanilla, tintura de Arnica montana y propóleo) y bálsamo de Perú. La alergia a los corticosteroides debe sospecharse cuando las lesiones no mejoran o empeoran con la terapia y deben confirmarse con prueba de parche ${ }^{(19)}$.

Los ingredientes de los medicamentos tópicos y los remedios caseros desempeñaron el papel más importante como sensibilizadores en el área genital. En un informe de Francia, los perfumes, la clorhexidina, la hexamidina, el cloruro de benzalconio y el látex se mencionan como las causas más frecuentes de dermatitis alérgica de contacto en la piel vulvar ${ }^{(21)}$.

En un estudio realizado por Fisher sobre pacientes con dermatitis vulvar posterior al uso de aerosoles de higiene femenina, se observaron sensibilizaciones relevantes al cloruro de benzalconio, clorhexidina, miristato de isopropilo y perfume ${ }^{(22)}$. Giroux y Pratt identificaron el acrilato como el alérgeno relevante en producir la dermatitis alérgica de contacto en las toallas o pañales para incontinencia ${ }^{(23)}$.

En una publicación de diferentes instituciones de Estados Unidos en pacientes con dermatitis de contacto vulvar, los alérgenos más frecuentes y relevantes fueron las fragancias mix, el bálsamo de Perú, la benzocaína, el quaternium 15 y terconazol ${ }^{(19)}$.

En un estudio realizado en el Hospital Militar Central en pacientes con prurito vulvar, se encontraron como principales alérgenos: níquel, bálsamo de Perú, fragancias, cobalto, parafenildiamina, tiomerosal, formaldehído, neomicina, gentamicina, tiuram, benzocaína, quaternium y clorhexidina, en su orden ${ }^{(24)}$.

Las alergias a metales como el níquel también pueden presentarse en la región vulvar por contacto con botones de ropa, cuchillas de afeitar o transmisión de dedos después de manipular joyas $u$ otras fuentes externas; el níquel también es un componente de papel higiénico hecho de papel reciclado ${ }^{(13)}$. También está incluido el papel higiénico de color y los tintes a través de la ropa interior ${ }^{(25)}$.

\section{DIAGNÓSTICO DE LA}

\section{DERMATITIS IRRITATIVA Y ALÉRGICA EN LA REGIÓN VULVAR}

Mientras que la dermatitis aguda irritativa se desarrolla de minutos a horas después de la exposición al irritante, la dermatitis aguda alérgica de contacto requiere habitualmente de 24 a 48 horas después del contacto con los alérgenos antes de que aparezcan los síntomas; en las siguientes exposiciones, la respuesta se presenta más rápidamente. La reacción irritante alcanza su pico rápidamente y luego comienza a curarse ("fenómeno decrescendo"). La reacción alérgica, en contraste, es más retrasada ("fenómeno crescendo"). Ambas formas de dermatitis tienen las mismas características clínicas: eritema, edema, liquenificación, escoriaciones, descamación e hiperqueratosis. Generalmente hay ausencia de costras, ya que en la región vulvar, por la oclusión, produce aumento de la humedad ${ }^{(3)}$.

Gardner hace hincapié en que muchos casos de dermatitis crónica de contacto tienden a ser mal diagnosticados como distrofia hiperplásica vulvar ${ }^{(26)}$. Dado que no existe una prueba diagnóstica específica para la dermatitis irritativa, el diagnóstico se basa en la historia, especialmente en relación con el contacto con irritantes, el examen clínico y la exclusión de otras causas, en particular la alergia de contacto y las enfermedades infecciosas ${ }^{(27)}$. 
Una excelente entrevista a las pacientes ayuda a orientar el diagnóstico, es una parte esencial del proceso. Se debe indagar por todas las posibles exposiciones a la zona vulvar, lo que incluye jabones de uso personal, jabones íntimos, detergentes para la ropa, toallas higiénicas, protectores, toallitas húmedas, cremas tópicas, ungüentos, polvos, tintes en ropa interior o papel higiénico de color, agua excesivamente caliente, lavados abrasivos, espermicidas, juguetes sexuales, lubricantes, fragancias, entre otros. Además, no solo se debe indagar por productos que se aplican directamente en la zona vulvar, también es importante saber los posibles alérgenos o irritantes que pueden ser transferidos por las manos o dedos de la paciente desde otras áreas del cuerpo, como la cara (maquillaje) o la axila (desodorante) o del entorno ${ }^{(9)}$.

Las pruebas de parche se deben usar temprano en el proceso terapéutico en lugar de ser reservadas para aquellos pacientes que no responden al tratamiento ${ }^{(20,}$ 28).

Las series recomendadas son una serie estándar, una serie de medicamentos, los medicamentos tópicos del paciente, los remedios caseros y otros productos sospechosos. Una biopsia cutánea puede ser útil para establecer el diagnóstico de dermatitis de contacto, pero, generalmente, no es útil para el diagnóstico diferencial entre la dermatitis irritativa y alérgica ${ }^{(2)}$.

Los colorantes textiles tales como Disperse Orange 3 (un colorante azo) y Disperse Blue 35 y 153 (colorantes de antraquinona), presentes en ropa interior, han sido descritos como las causas de una dermatitis pigmentada y purpúrica ${ }^{(29)}$.

\section{GENERALIDADES DE LOS JABONES}

La superficie de la piel es ligeramente ácida, lo que da lugar al concepto del manto ácido ${ }^{(30)}$. La piel normal tiene un potencial de hidrógeno $(\mathrm{pH})$ entre 5,4 y 5,9 y una flora bacteriana. El uso de jabón con un pH alto produce un aumento en el $\mathrm{pH}$ de la piel, lo que, a su vez, causa un aumento en el efecto deshidratante, irritabilidad y alteración en la flora bacteriana. La mayoría de los jabones y champús disponibles en el mercado no revelan su $\mathrm{pH}$, pero según estudios se ha demostrado que la mayoría de los jabones tienen un $\mathrm{pH}$ dentro del rango de $9-10^{(31)}$.
Realizar una adecuada elección de productos de limpieza es importante porque nos ayuda a mejorar la hidratación de la piel, proporcionar beneficios humectantes y minimizar el daño cutáneo causado por los surfactantes. Los surfactantes pueden dañar las estructuras de las proteínas y solubilizar los lípidos. Los jabones se obtienen de mezclar ácidos grasos (de origen animal o vegetal) con un álcali (hidróxido de sodio o potasio), por eso son definidos como las sales alcalinas de ácidos grasos, son los surfactantes más antiguos y son bastante agresivos. Los syndets, en lugar de ácidos grasos de origen animal o vegetal, utilizan detergentes sintéticos y varían en composición y tipos de surfactantes (aniónicos, catiónicos, anfótericos y no iónicos); tienen un $\mathrm{pH}$ entre 5,5 y 7,0. Estos nuevos productos para la limpieza de la piel también contienen conservantes, fragancias y, en ciertos casos, emolientes, humectantes y nutrientes para la piel ${ }^{(32)}$.

Las compañías de cosméticos comercializan una amplia variedad de detergentes, proponiéndolos como productos muy suaves. Sin embargo, no existe un acuerdo internacional sobre los criterios para establecer la suavidad de los limpiadores y, en realidad, varios productos para pieles sensibles tienen considerables efectos irritantes ${ }^{(33,34)}$.

Los limpiadores incluyen los jabones comunes y los syndets (detergentes sintéticos, no jabones) introducidos, inicialmente, como barras y, después, como detergentes líquidos (gel hidratante para el cuerpo/ ducha) ${ }^{(35-37)}$.

Los principales componentes de los jabones son los tensoactivos (agentes activos de superficie): un agente de superficie activa (surfactante) es, como su nombre lo indica, una sustancia que se adsorbe a una superficie de gas o líquido y a la superficie de los sólidos ${ }^{(38)}$, disminuyendo la tensión superficial en la piel y eliminando la suciedad en forma emulsionada ${ }^{36,39)}$.

Si bien de la manera más simple de limpieza (limpieza por afinidad), la suciedad hidrofílica solo puede eliminarse con agua, y la suciedad lipofílica soluble en grasa solo por los aceites, los limpiadores basados en surfactantes (jabones tradicionales y syndets modernos) permiten la eliminación de la suciedad al solubilizarla en micelas eliminadas sucesivamente por el agua ${ }^{(32)}$. 


\section{TIPOS DE SURFACTANTES}

Los surfactantes poseen regiones polares y no polares. La región polar o hidrofílica de la molécula puede tener una carga positiva o negativa, que da lugar a tensoactivos catiónicos o aniónicos, respectivamente ${ }^{(38,40)}$.

Es importante categorizar los productos químicos de acuerdo con sus porciones polares, ya que la porción no polar se compone generalmente de grupos alquilo. Los principales grupos polares que se encuentran en la mayoría de los surfactantes se pueden dividir en 4 tipos (tabla 3) ${ }^{(38)}$.

\section{AGENTES ANIÓNICOS}

Se usan comúnmente como surfactantes primarios en limpiadores, debido a que, por ser económicos, moderan el costo del producto final ${ }^{39,41,42)}$.

El SLS es una emulsionante aniónico, detergente y agente humectante en ungüentos, productos de cuidado personal y otras preparaciones farmacéuticas. Es un potente antimicrobiano ${ }^{(43-45)}$, que también se ha descrito que es virustático ${ }^{(46)}$. Es un agente altamente irritativo, por lo que ha sido importante incluirlo en los estudios de investigación de irritación de la piel ${ }^{(47)}$.

Puede interactuar fuertemente con la piel causando grandes alteraciones en las propiedades de barrera, tanto en el estrato córneo como en las estructuras de lípidos y proteínas ${ }^{(48)}$. Es de rápida acción, no alergénico y constante en su toxicidad ${ }^{(49)}$; estas propiedades hacen que el tensoactivo sea un irritante agudo y acumulativo, adecuado y útil en estudios de investigación biológica. En los últimos años se ha convertido en el agente más importante en las investigaciones de dermatitis de contacto irritativa ${ }^{(14,47,50)}$.

El etoxilato correspondiente (laureth sulfato de sodio [SLES]) es el tensoactivo primario principal en gel de baño/ducha corporal y champú, debido a su buen poder de limpieza y su bajo costo; también tiene algún potencial irritante ${ }^{(51)}$.

\section{AGENTES CATIÓNICOS}

Los agentes catiónicos, cargados positivamente, tienen propiedades detergentes más bajas que los tensoactivos aniónicos, pero mayor potencial desinfectante

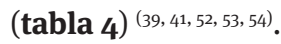

Tabla 4. Tipos de jabones

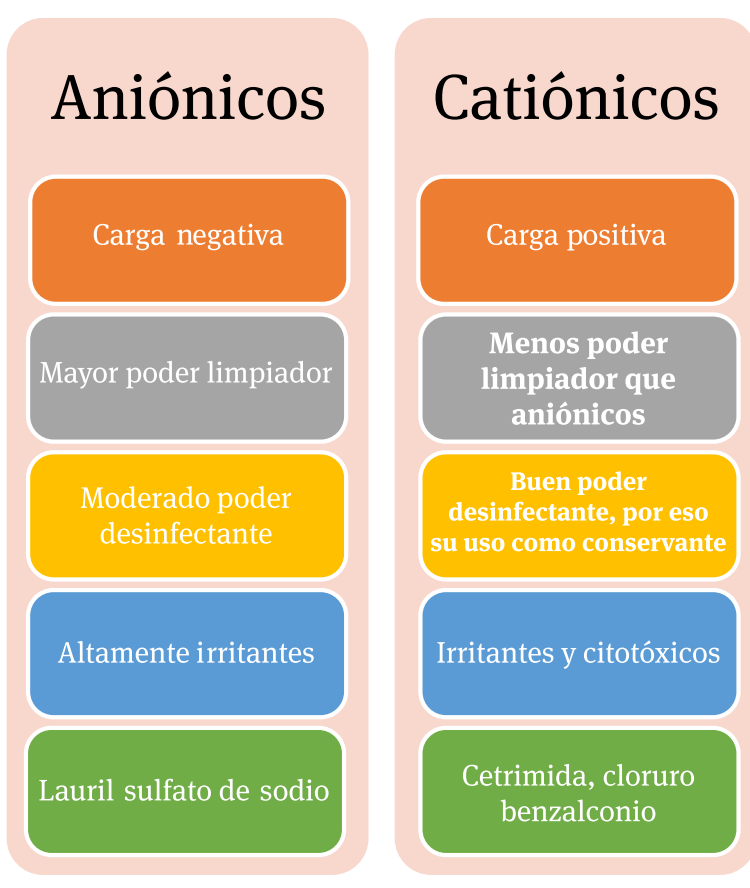

\section{Anfotéricos}
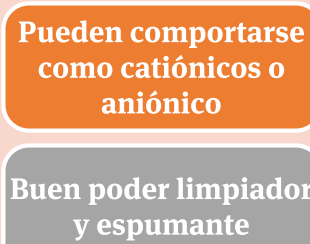

y espumante

Moderada actividad antimicrobiana

Bajo potencial

irritante - compatibilidad con diferentes $\mathrm{pH}$

Cocamidopropyl betaine

\section{No Iónicos}

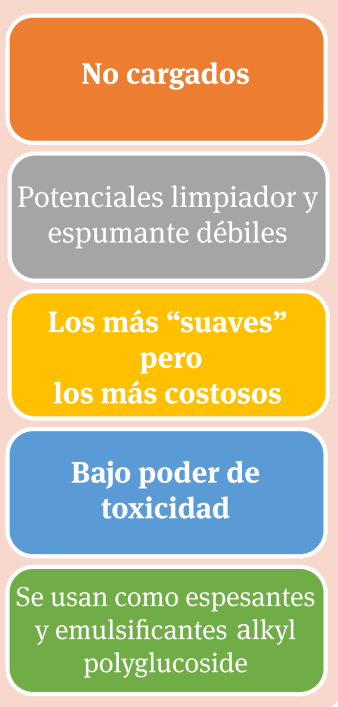




\section{AGENTES ANFOTÉRICOS}

Tienen las propiedades detergentes de los tensoactivos aniónicos y las propiedades desinfectantes de los tensoactivos catiónicos. $\mathrm{Su}$ actividad depende del $\mathrm{pH}$ de los medios en los que se utilizan ${ }^{(55)}$. Tienen gran poder de limpieza, características de espuma, actividad antimicrobiana moderada y compatibilidad con diferentes $\mathrm{pH}^{(39,41)}$.

El más importante es el cocamidopropil betaina. Es común en el champú y los limpiadores líquidos, tiene un moderado potencial de irritación y se considera como un generador de viscosidad y espuma ${ }^{(56)}$. A su vez, este compuesto es el responsable de aumentar los casos de dermatitis de contacto alérgica; sin embargo, en los últimos estudios, los sensibilizadores reales en estos casos parecen ser impurezas, como el compuesto original dimetilaminopropilamina, que puede estar presente en algunas fuentes del surfactante ${ }^{(52,57,58)}$.

\section{AGENTES NO IÓNICOS}

Se consideran los surfactantes más "suaves", pero también los más costosos en el mercado ${ }^{(39,59)}$. Sin embargo, algunos autores notaron que este grupo de surfactantes altera la capa lipídica de la piel más que los aniónicos, porque pueden solubilizar los ácidos grasos y el colesterol en la piel ${ }^{35)}$.

Se utilizan como espesantes para champús y detergente líquido, emulsionantes industriales y agentes de suspensión en cosméticos, productos farmacéuticos y alimentos ${ }^{(39)}$, detergentes textiles, estabilizadores de espuma en detergentes para lavado de ropa y lavavajillas ${ }^{(40)}$.

Una importante propiedad de los surfactantes es la concentración crítica de las micelas (CMC), la cual es definida como la concentración de tensoactivos por encima de los cuales se forman micelas espontáneamente $(32,60)$.

En concentraciones bajas, los surfactantes añadidos al agua se organizarán en la superficie, con su cola hidrofóbica (la parte no polar) proyectada en el exterior. A medida que la superficie se llena de más tensioactivos añadidos, sus moléculas comienzan a formar aglomerados (conocidos como micelas) en el líquido. Al llegar a la CMC, cualquier adición de surfactantes simplemente aumentará el número de micelas. Los sur- factantes caracterizados por un elevado valor de CMC (como el lauril sulfato) han demostrado ser irritantes primarios para la piel ${ }^{(35,61,62)}$.

La CMC está influenciada por el grado de carga del componente hidrofílico; normalmente, los tensioactivos aniónicos y catiónicos tienen una CMC más alta que los agentes no iónicos y, por tanto, se vuelven más agresivos. La reducción de CMC puede ser el resultado de una combinación en syndets de diferentes tipos de surfactantes, como el lauril sulfato y los agentes anfotéricos o no iónicos (con baja CMC). En consecuencia, disminuye el poder irritante ${ }^{(62)}$.

\section{EFECTOS DE LOS TENSOACTIVOS EN LA PIEL}

Los tensoactivos disminuyen la tensión superficial, alterando la energía de cohesión en la superficie del agua y eliminando los residuos en forma emulsionada ${ }^{(52)}$.

En particular, los surfactantes tienen los siguientes efectos ${ }^{(36,39)}$ :

- Limpieza: para eliminar la suciedad de la piel y el cabello.

- Espuma: algunos de los tipos de surfactantes tienen mayor poder espumante.

- Humectación: para aumentar el contacto entre el producto y el sustrato (suciedad).

- Emulsionante: para organizarse en la interfaz entre dos líquidos inmiscibles. Esto permite la preparación de emulsiones.

- Solubilización: para introducir sustancias insolubles en preparaciones donde necesita preservar la claridad.

Los efectos de los surfactantes en la piel se han estudiado ampliamente en condiciones in vitro e in vivo ${ }^{(63,}$ ${ }^{64)}$. Se ha demostrado que estos inducen cambios bioquímicos en la piel cuando se aplican tópicamente, por lo cual se han convertido en modelos de irritantes ampliamente utilizados en la investigación de la irritación de la piel ${ }^{(65,66)}$.

Varios tensoactivos son irritantes: sustancias que afectarán directamente a la piel por acción citotóxica directa y sin prioridad o inmunización inmunológica precedente (hipersensibilidad retardada) ${ }^{(67)}$. 
Los efectos dañinos sobre la piel son los siguientes:

- Alcalización.

- Eliminación de lípidos, que potencia la unión a las proteínas de los queratinocitos, y edema, al exponer nuevos sitios de unión a la queratina ${ }^{(68)}$.

- Daño a las proteínas de la piel, la interacción con las queratinas y su desnaturalización ${ }^{(68)}$. Produce edema de las membranas celulares y las fibras de colágeno. En condiciones de lavado, hay un edema transitorio debido a las interacciones entre los surfactantes y estas proteínas, que conduce a la hiperhidratación. Esto, generalmente, es seguido por disminución del edema por la evaporación del agua, lo que produce resequedad, aspereza, rigidez y descamación como consecuencias tardías ${ }^{(35,62)}$.

- Citotoxicidad expresada con lisis celular cuando el daño de la barrera cutánea y sus alteraciones de la permeabilidad se vuelven irreparables ${ }^{(39)}$.

- Irritación relacionada con la exposición temporal del agente limpiador a la piel, a su concentración y a su uso frecuente. Se sabe que los surfactantes son irritantes para la piel, lo que produce dermatitis de contacto irritativa, que se vuelve crónica después de exposiciones frecuentes y prolongadas. El daño de barrera y la liberación de citocinas derivadas de los queratinocitos pueden provocar irritación de la piel, eritema y prurito ${ }^{(56)}$.

\section{JABONES ÍNTIMOS}

El estrato córneo no es una barrera inerte y las sustancias limpiadoras pueden afectar profundamente la estructura y función de la barrera cutánea ${ }^{(69)}$. Como se revisó previamente, los jabones pueden ser irritantes, por ejemplo, el SLS recientemente fue desaconsejado por la European Roundtable Meeting on Best Practice Healthy Infant Skin Care, para el cuidado de la piel de los niños ${ }^{(70)}$. En el mercado existe la oferta de jabones sintéticos, que, tal vez, sean los menos agresivos para la piel ${ }^{(71)}$. Sin embargo, no hay consenso sobre el uso de jabones en la región genital (tabla 5).

En este artículo queremos mostrar los componentes de algunos de los jabones que se comercializan bajo la etiqueta de “jabón íntimo", lo que sugiere para las pacientes que es un producto especializado para una zona delicada con diferencias con respecto a los otros jabones para el resto del cuerpo, por lo cual, en teoría, deberían ser más suaves y se podrían aplicar con segu- ridad en la región genital.

Se evaluaron 18 marcas de sustancia limpiadoras disponibles en el mercado colombiano para uso exclusivo genital y se encontró que ninguna de ellas reporta en su etiqueta la concentración o porcentaje de los diferentes agentes constitutivos, ni su valor de potencial de hidrógeno $(\mathrm{pH})$.

De acuerdo con el tipo de surfactantes que contiene cada sustancia limpiadora se encontró lo siguiente: el $88 \%$ contiene tensoactivos aniónicos, el 18\% contiene SLS y el 62\% contiene SLES, los cuales fueron considerados como potentes irritantes de la piel. El 88\% contiene algún tipo de tensoactivo catiónico, ninguno del tipo cloruro de benzalconio, ni cetrimida, los cuales son los más descritos en la literatura como agentes citotóxicos e irritantes. El 61\% contiene algún tipo de tensoactivos anfotéricos, como el cocamidopropil betaina o cocoanfoacetato, considerados con potencial de irritación moderada. El 62\% contienen tensoactivos no iónicos como el propietilenglicol (PEG) o ácidos grasos como emulsificante; estos son considerados importantes alérgenos. El 94\% contienen perfumes, el 50\% contiene parabenos o metilisotiazolinona, e incluso el 33\% contiene mezclas de parabenos considerados como conservantes con uso discutido en la industria cosmética.

Con este análisis de los componentes de algunos de estos “jabones íntimos”, vemos que contienen los mismos detergentes irritantes que el resto de los jabones, como el SLS, también perfumes, parabenos y potentes sensibilizantes, como la metilisotiazolinona.

Es preocupante el mercadeo masivo que se le da a este tipo de jabones, el aumento exponencial de su uso y el hecho que las pacientes consideren que deben usar este tipo de sustancias en la piel del epitelio parcialmente queratinizado de la vulva o incluso en la mucosa vaginal. Además, por lo general, las mujeres asocian síntomas genitales como posibles infecciones a las cuales se deben combatir con jabones "especializados", que solo agravan los problemas de piel de esta zona, sensibilizando y produciendo dermatitis de contacto.

\section{CONCLUSIONES}

La piel vulvar es un tejido especializado con propiedades estructurales y funcionales muy diferentes con respecto al resto de piel. Sus características his- 
Tabla 5. Componentes de jabones íntimos

\begin{tabular}{|c|c|c|c|c|c|c|c|c|}
\hline $\begin{array}{c}\text { Tipos de } \\
\text { surfactante }\end{array}$ & Saforelle® & Eucerin ${ }^{\circledR}$ & Intibon $®$ & Lactacyd@ & $\begin{array}{c}\text { Lactacy Pro } \\
\text { Bio@ }\end{array}$ & Nivea ${ }^{\circledR}$ & Lux® & $\begin{array}{c}\text { Nosotras } ® \\
\text { Natural }\end{array}$ \\
\hline \multirow{4}{*}{ Aniónicos } & & $\begin{array}{c}\text { Myreth sulfato } \\
\text { de sodio }\end{array}$ & $\begin{array}{l}\text { Lauril sulfato } \\
\text { de sodio }\end{array}$ & $\begin{array}{l}\text { Lauril sulfato } \\
\text { de sodio }\end{array}$ & $\begin{array}{l}\text { Lauril sulfato } \\
\text { de sodio }\end{array}$ & & & \\
\hline & & & $\begin{array}{c}\text { Laureth sulfato } \\
\text { de sodio }\end{array}$ & $\begin{array}{l}\text { Laureth sulfato } \\
\text { de magnesio }\end{array}$ & $\begin{array}{c}\text { Laureth sulfato } \\
\text { de sodio }\end{array}$ & $\begin{array}{c}\text { Laureth sulfato } \\
\text { de sodio }\end{array}$ & $\begin{array}{c}\text { Laureth sulfato } \\
\text { de sodio }\end{array}$ & $\begin{array}{l}\text { Lauril éter } \\
\text { sulfato }\end{array}$ \\
\hline & & & Laureth 10 & \begin{tabular}{|c|} 
Lauril \\
sulfosuccinato \\
disódico \\
\end{tabular} & & & $\begin{array}{l}\text { Trideceth } \\
\text { sulfato de } \\
\text { sodio } \\
\end{array}$ & $\begin{array}{l}\text { Trideceth } \\
\text { sulfato de } \\
\text { sodio } \\
\end{array}$ \\
\hline & & & & Laureth 10 & & & & \\
\hline \multirow{5}{*}{ Catiónicos } & & Bisabol & Bisabol & & & Bisabol & & Fenoxietanol \\
\hline & & $\begin{array}{c}\text { Policuaternario } \\
10\end{array}$ & $\begin{array}{c}\text { Diazolidinilure } \\
\mathrm{a}\end{array}$ & Fenoxietanol & & & $\begin{array}{l}\text { Lactato de } \\
\text { potasio }\end{array}$ & $\begin{array}{c}\text { DMDM } \\
\text { hidantoína }\end{array}$ \\
\hline & & & $\begin{array}{c}\text { Metil parabeno } \\
\text { de sodio }\end{array}$ & $\begin{array}{c}\text { Metilisotiazoli } \\
\text { nona }\end{array}$ & $\begin{array}{c}\text { Metil parbeno } \\
1,53 \mathrm{mg} / \mathrm{dL}\end{array}$ & & & $\begin{array}{l}\text { Metil y propil } \\
\text { parabeno de } \\
\text { sodio }\end{array}$ \\
\hline & & & $\begin{array}{c}\text { Yodo propinil } \\
\text { butil } \\
\text { carbamato }\end{array}$ & & & & & \\
\hline & & $\begin{array}{c}\text { Benzoato de } \\
\text { sodio }\end{array}$ & & & & $\begin{array}{l}\text { Benzoato de } \\
\text { sodio }\end{array}$ & $\begin{array}{c}\text { Benzoato de } \\
\text { sodio }\end{array}$ & \\
\hline \multirow{2}{*}{ Anfotéricos } & $\begin{array}{l}\text { Cocamidopro- } \\
\text { pil betaina }\end{array}$ & $\begin{array}{l}\text { Cocoanfoace- } \\
\text { tato de sodio }\end{array}$ & & $\begin{array}{l}\text { Cocamidopro- } \\
\text { pil betaina }\end{array}$ & & $\begin{array}{l}\text { Cocamidopro- } \\
\text { pil betaina }\end{array}$ & $\begin{array}{l}\text { Cocamidopro- } \\
\text { pil betaina }\end{array}$ & $\begin{array}{l}\text { Cocamidopro- } \\
\text { pil betaina }\end{array}$ \\
\hline & Cocamide DEA & $\begin{array}{l}\text { Lauril } \\
\text { poliglucósido }\end{array}$ & Cocamide MEA & Cocamide MEA & Cocamide DEA & Glicerina & Cocamide MEA & Decil glucósido \\
\hline \multirow[t]{2}{*}{ No iónicos } & $\begin{array}{c}\text { Propilenglicol/ } \\
\text { Polisorbato } 20 \\
\text { /Octoxinol - } 9\end{array}$ & $\begin{array}{l}\text { PEG } 40 \text { aceite } \\
\text { de ricino } \\
\text { hidrogenado }\end{array}$ & $\begin{array}{c}\text { Glicerina/ } \\
\text { Glicol } \\
\text { diesterato }\end{array}$ & $\begin{array}{c}\text { Propilenglicol/ } \\
\text { Glicol } \\
\text { diesterato }\end{array}$ & & $\begin{array}{l}\text { PEG } 40 \text { aceite } \\
\text { de ricino } \\
\text { hidrogenado/ } \\
\text { PEG } 7 \text { glicerol } \\
\text { cocoato }\end{array}$ & PPG 9 & Glicerina \\
\hline & $\begin{array}{c}\text { PEG } 6 \\
\text { caprílico/ } \\
\text { Caprico } \\
\text { glicéridos }\end{array}$ & $\begin{array}{c}\text { PEG } 200 \\
\text { palmato } \\
\text { glicerílico } \\
\text { hidrogenado }\end{array}$ & $\begin{array}{l}\text { Xilitol/ } \\
\text { Lactitol }\end{array}$ & $\begin{array}{c}\text { PEG } 7 \text { Glicerol } \\
\text { cocoato/ } \\
\text { Laurato de } \\
\text { glicerol/Oleato } \\
\text { de PEG } 55\end{array}$ & & $\begin{array}{c}\text { PEG } 200 \\
\text { palmato } \\
\text { glicerílico } \\
\text { hidrogenado }\end{array}$ & $\begin{array}{c}\text { Glicerina/ } \\
\text { Glicol } \\
\text { diesterato }\end{array}$ & $\begin{array}{l}\text { PEG } 150 \\
\text { disterato }\end{array}$ \\
\hline $\begin{array}{c}\text { Sustancia buffer - } \\
\text { Humectante }\end{array}$ & & $\begin{array}{l}\text { Ácido láctico/ } \\
\text { Salicilato de } \\
\text { sodio }\end{array}$ & Ácido láctico & Ácido láctico & $\begin{array}{c}\text { Ácido láctico/ } \\
\text { Ácido } \\
\text { fosfórico }\end{array}$ & Ácido láctico & Ácido láctico & Ácido láctico \\
\hline
\end{tabular}




\begin{tabular}{|c|c|c|c|c|c|c|c|c|c|}
\hline Protex $®$ & Ellas $®$ & Íntimo $®$ & Recamier $®$ & Cautiva $®$ & $\begin{array}{c}\text { Organyc }{ }^{\text {(Madrid) }}\end{array}$ & $\begin{array}{l}\text { Idoky® } \\
\text { (España) }\end{array}$ & $\begin{array}{c}\text { Intime-Elle }{ }^{\circledR} \\
\text { (España) }\end{array}$ & $\begin{array}{c}\text { Simply } \\
\text { Delicate }{ }^{\circledR} \\
(\text { Avon } ®) \\
\end{array}$ & Babaria ${ }^{\circledR}$ \\
\hline \multirow[t]{2}{*}{$\begin{array}{c}\text { Laureth sulfato } \\
\text { de sodio }\end{array}$} & $\begin{array}{c}\text { Laureth sulfato } \\
\text { de sodio }\end{array}$ & & $\begin{array}{c}\text { Laureth sulfato } \\
\text { de sodio }\end{array}$ & $\begin{array}{c}\text { Laureth sulfato } \\
\text { de sodio }\end{array}$ & & & & $\begin{array}{c}\text { Laureth sulfato } \\
\text { de sodio }\end{array}$ & $\begin{array}{c}\text { Laureth sulfato } \\
\text { de sodio }\end{array}$ \\
\hline & & $\begin{array}{l}\text { Lauril éter } \\
\text { sulfato de } \\
\text { sodio }\end{array}$ & $\begin{array}{l}\text { Lauril éter } \\
\text { sulfato de } \\
\text { sodio }\end{array}$ & & $\begin{array}{l}\text { Coco sulfato de } \\
\text { sodio }\end{array}$ & & & & \\
\hline \multirow[t]{2}{*}{ Laureth 10} & & & & & & & $\begin{array}{l}\text { Laureth 2- } \\
\text { Laureth } 3\end{array}$ & & \\
\hline & & & & & & $\begin{array}{c}\text { Ácido } \\
\text { dehidroacético }\end{array}$ & Bisabol & & \\
\hline \multirow[t]{6}{*}{$\begin{array}{c}\text { Policuaternario } \\
7\end{array}$} & $\begin{array}{c}\text { Metil } \\
\text { parabeno/ } \\
\text { Propil } \\
\text { parabeno }\end{array}$ & & $\begin{array}{c}\text { DMDM } \\
\text { hidantoína }\end{array}$ & & & & $\begin{array}{l}\text { Imidazolidini- } \\
\text { lurea/ } \\
\text { Centaurea } \\
\text { cyanus } \\
\end{array}$ & $\begin{array}{l}\text { Imidazolidini- } \\
\text { lurea }\end{array}$ & $\begin{array}{c}\text { Yodo propinil } \\
\text { butil } \\
\text { carbamato }\end{array}$ \\
\hline & & & $\begin{array}{l}\text { Yodo propinil } \\
\text { butil } \\
\text { carbamato }\end{array}$ & Metil parabeno & & & $\begin{array}{c}\text { Metilisotiazo- } \\
\text { linona/ } \\
\text { metil cloro } \\
\text { tiazolinona }\end{array}$ & & $\begin{array}{c}\text { Metilisotiazo- } \\
\text { linona }\end{array}$ \\
\hline & & & $\begin{array}{c}\text { Propil } \\
\text { parabeno/ } \\
\text { metil } \\
\text { parabeno de } \\
\text { sodio } \\
\end{array}$ & & & & & & Triclosán \\
\hline & & & Triclosán & & $\begin{array}{c}\text { Benzoato de } \\
\text { sodio }\end{array}$ & & & & \\
\hline & $\begin{array}{l}\text { Cocamidopro- } \\
\text { pil betaina }\end{array}$ & & $\begin{array}{l}\text { Cocamidopro- } \\
\text { pil betaina }\end{array}$ & $\begin{array}{c}\text { Cocamidopro- } \\
\text { pil betaina }\end{array}$ & Cocoglucósido & $\begin{array}{c}\text { Cocoglucósido } \\
\text { /Laurato de } \\
\text { sacarosa }\end{array}$ & $\begin{array}{l}\text { Cocoanfoace- } \\
\text { tato de sodio }\end{array}$ & & \\
\hline & & & & & & & $\begin{array}{c}\text { Cocamidopro- } \\
\text { pil betaina }\end{array}$ & & $\begin{array}{c}\text { Cocamidopro- } \\
\text { pil betaina }\end{array}$ \\
\hline \multirow[t]{3}{*}{ Cocamide MEA } & Cocamide DEA & & Cocamide MEA & $\begin{array}{c}\text { Cocamide } \\
\text { DEA/ } \\
\text { Glicerina } \\
\end{array}$ & & Decil glucósido & Cocoglucósido & & \\
\hline & $\begin{array}{c}\text { Lauril } \\
\text { glucósido/ } \\
\text { Propilenglicol/ } \\
\text { Glicerina }\end{array}$ & $\begin{array}{l}\text { Propilenglicol/ } \\
\text { Glicerina/ } \\
\text { Caléndula/ } \\
\text { Sorbitol }\end{array}$ & $\begin{array}{c}\text { Propilenglicol/ } \\
\text { Glicerina }\end{array}$ & $\begin{array}{l}\text { PEG } 120 \text { metil } \\
\text { glucosa } \\
\text { triolato }\end{array}$ & $\begin{array}{c}\text { Glicerina/ } \\
\text { Glicerol }\end{array}$ & $\begin{array}{c}\text { Glicerina/ } \\
\text { Glicerol }\end{array}$ & $\begin{array}{c}\text { Lauril } \\
\text { glucósido/ } \\
\text { Polisorbato } 20\end{array}$ & $\begin{array}{c}\text { Glicerina/ } \\
\text { Polisorbato } 20\end{array}$ & Glicerina \\
\hline & $\begin{array}{l}\text { PEG } 40 \text { aceite } \\
\text { de ricino } \\
\text { hidrogenado } \\
\text { /PEG } 150 \\
\text { disterato }\end{array}$ & & & & & & $\begin{array}{l}\text { Gliceril } \\
\text { oleato/ } \\
\text { Glicerina }\end{array}$ & & \\
\hline Ácido láctico & Ácido láctico & Ácido láctico & Ácido láctico & Ácido láctico & & & Ácido láctico & & \\
\hline
\end{tabular}




\begin{tabular}{|c|c|c|c|c|c|c|c|c|}
\hline $\begin{array}{l}\text { Tipos de } \\
\text { surfactante }\end{array}$ & Saforelle $®$ & Eucerin $\circledast$ & Intibon $\circledast$ & Lactacyd $₫$ & Lactacy Pro Bio@ & Nivea® & Lux® & $\begin{array}{c}\text { Nosotras } ® \\
\text { Natural }\end{array}$ \\
\hline $\begin{array}{l}\text { Desnaturalizante y } \\
\text { sustancia buffer }\end{array}$ & $\begin{array}{l}\text { Hidróxido de } \\
\text { sodio }\end{array}$ & & & $\begin{array}{l}\text { Hidróxido de } \\
\text { sodio }\end{array}$ & $\begin{array}{l}\text { Hidróxido de } \\
\text { sodio }\end{array}$ & & & \\
\hline $\begin{array}{c}\text { Viscosidad- } \\
\text { Enmascaramiento }\end{array}$ & $\begin{array}{l}\text { Cloruro de } \\
\text { sodio }\end{array}$ & & & & & $\begin{array}{l}\text { Cloruro de } \\
\text { sodio }\end{array}$ & $\begin{array}{l}\text { Cloruro de } \\
\text { sodio }\end{array}$ & \\
\hline Agente quelante & $\begin{array}{c}\text { EDTA } \\
\text { tetrasódico }\end{array}$ & & & & & & & $\begin{array}{c}\text { EDTA } \\
\text { tetrasódico }\end{array}$ \\
\hline $\begin{array}{c}\text { Tónico- } \\
\text { Enmascaramiento }\end{array}$ & $\begin{array}{c}\text { Aceite de } \\
\text { lavanda } \\
\text { angustifolia } \\
\end{array}$ & & & & & & & \\
\hline Acondicionador & $\begin{array}{c}\text { Arctium lappa } \\
\text { root extract } \\
\text { (extracto de } \\
\text { raíz de } \\
\text { bardana) }\end{array}$ & & & & & & & \\
\hline \multirow[t]{2}{*}{$\begin{array}{c}\text { Perfume- } \\
\text { Aromatizante }\end{array}$} & $\begin{array}{c}\text { Perfume/ } \\
\text { Citronelol/ } \\
\text { Geraniol }\end{array}$ & $\begin{array}{c}\text { Perfume/ } \\
\text { Farnesol/ } \\
\text { Metil } \\
\text { cinamato/ } \\
\text { Butil fenil } \\
\text { metil propionil } \\
\end{array}$ & Fragancia & Perfume & Perfume & Perfume & $\begin{array}{c}\text { Perfume/ } \\
\text { Citronelol/ } \\
\text { Butil fenil } \\
\text { metil propionil }\end{array}$ & Fragancia \\
\hline & $\begin{array}{c}\text { Limoneno/Lina } \\
\text { lool }\end{array}$ & $\begin{array}{c}\text { Alfa isometil } \\
\text { ionona/ } \\
\text { Linalool }\end{array}$ & & & & & LINALOL & \\
\hline $\begin{array}{l}\text { Emulsificante- } \\
\text { Antiestático }\end{array}$ & $\begin{array}{c}\text { Dimetil } \\
\text { esteramina }\end{array}$ & & & & & & & \\
\hline \multicolumn{9}{|l|}{$\begin{array}{c}\text { Buffer -Agente } \\
\text { quelante }\end{array}$} \\
\hline $\begin{array}{c}\text { Emulsión } \\
\text { estabilizadora }\end{array}$ & & & $\begin{array}{l}\text { Hidroxietil- } \\
\text { celulosa }\end{array}$ & & \begin{tabular}{|c|}
$\begin{array}{c}\text { Hidroxietilcelul } \\
\text { osa }\end{array}$ \\
\end{tabular} & & $\begin{array}{l}\text { Hidroxietil- } \\
\text { celulosa }\end{array}$ & \\
\hline \multirow{2}{*}{$\begin{array}{l}\text { Humectante- } \\
\text { Acondicionador }\end{array}$} & Caléndula & & $\begin{array}{l}\text { Caléndula/ } \\
\text { Extracto de } \\
\text { flores }\end{array}$ & $\begin{array}{c}\text { Suero de leche } \\
\text { en polvo }\end{array}$ & Lactosuero & $\begin{array}{l}\text { Extracto de } \\
\text { flores }\end{array}$ & & $\begin{array}{l}\text { Extracto de } \\
\text { aloe vera y } \\
\text { manzanilla }\end{array}$ \\
\hline & & & & & & $\begin{array}{l}\text { Pantenol/ } \\
\text { Glicina } \\
\text { de soya/ } \\
\text { Tocoferol }\end{array}$ & & \\
\hline $\begin{array}{l}\text { Humectante- } \\
\text { Emoliente }\end{array}$ & & & & & & & $\begin{array}{l}\text { Isopropil } \\
\text { palmitato }\end{array}$ & \\
\hline $\begin{array}{c}\text { Formación de } \\
\text { película } \\
\end{array}$ & & & & & $\begin{array}{c}\text { Copolímero de } \\
\text { acrilatos }\end{array}$ & & $\begin{array}{c}\text { Copolímero de } \\
\text { acrilatos }\end{array}$ & \\
\hline $\begin{array}{l}\text { Prebiótico- } \\
\text { Preservante }\end{array}$ & & & & & $\begin{array}{l}\text { Oligosacáridos } \\
\text { de alfa glucano }\end{array}$ & & & \\
\hline \multirow{2}{*}{ Solvente } & Agua & Agua & Agua & $\begin{array}{c}\text { Agua } \\
\text { purificada }\end{array}$ & Agua & Agua & AGUA & Agua \\
\hline & & $\begin{array}{l}\text { Salicilato de } \\
\text { bencilo }\end{array}$ & & & & & & \\
\hline
\end{tabular}




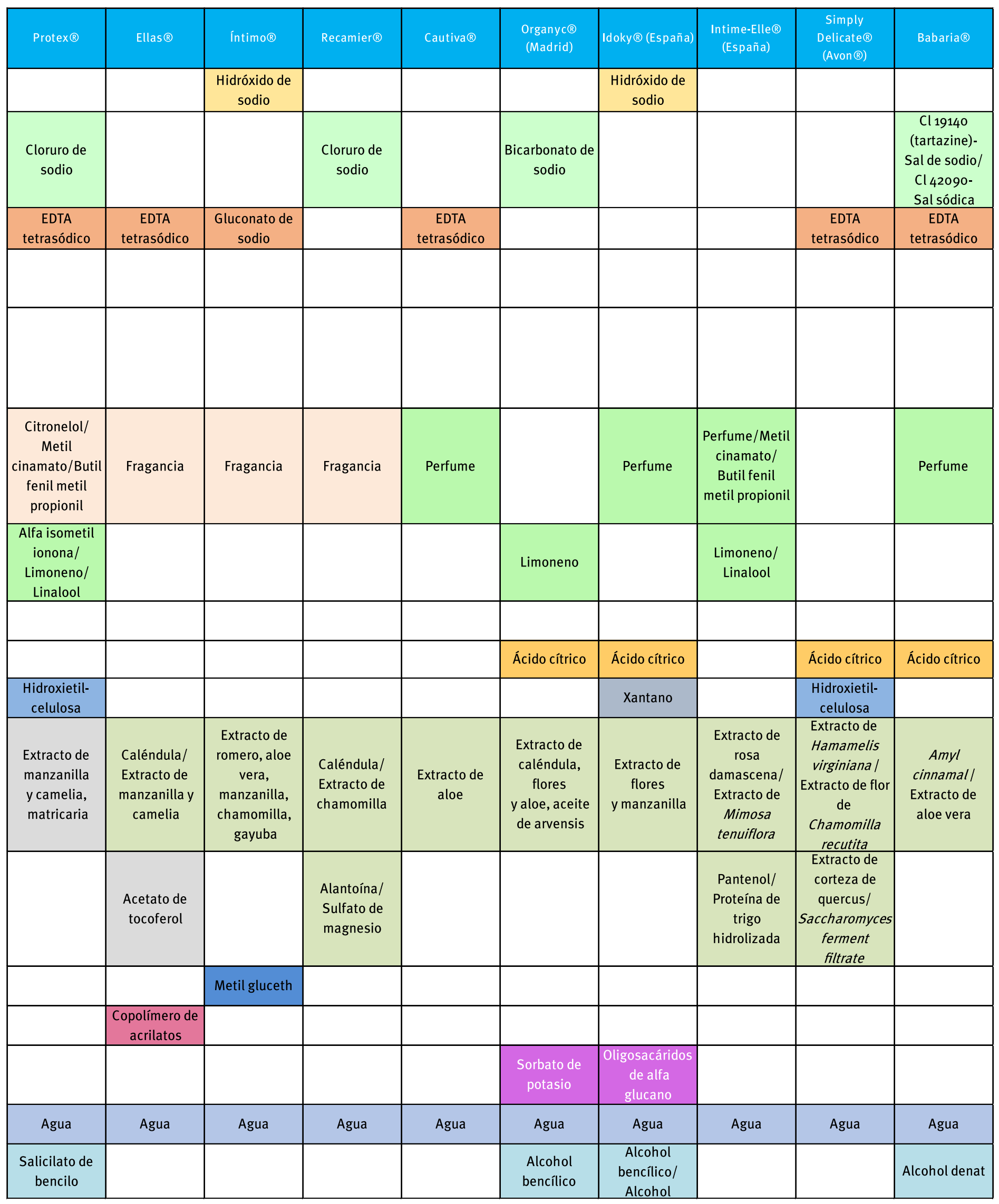


tológicas hacen que sea más sensible; además, está expuesta todo el tiempo a la humedad y fricción en condiciones que no se pueden modificar. Los efectos no deseados de los productos aplicados en la región vulvar en su presentación clínica en dermatitis de contacto e irritativa son diferentes en otras partes del cuerpo. Todas las pruebas que realizan las comparan con la piel de la cara anterior de antebrazos, que es una piel muy similar, pero no es igual. Es importante el estudio de esta condición; un diagnóstico temprano $\mathrm{y}$ acertado nos orienta para realizar un tratamiento efectivo eliminando los síntomas y ayudar a restaurar la barrera epitelial dañada, disminuir la inflamación, calmar el dolor y el prurito. Es indispensable la realización de prueba de parche para descartar dermatitis de contacto alérgica y, según su relevancia, evitar su contacto.

Los médicos necesitan documentar las propiedades de las sustancias limpiadoras para aconsejar o desaconsejar su uso, ya que algunos jabones, recomendados para "pieles sensibles", algunas veces pueden contener agentes potentemente agresivos que generan trastornos inflamatorios en la piel. Es necesario regular por parte del Invima la concentración de los principales alérgenos, ya que eso facilitaría la elección del limpiador menos citotóxico. No hay acuerdos internacionales sobre la definición de limpiadores “suaves”.

Es necesario realizar estudios de prevalencia de dermatitis de contacto o efectos secundarios en paciente con uso permanente de jabones íntimos.

\section{REFERENCIAS}

1. Farage MA, Miller KW, Ledger WJ. Determining the cause of vulvovaginal symptoms. Obstet Gynecol Surv 2008;63(7):445-64. Lever WF, SchaumburgLever G. 1983. Histopathology of the Skin. Philadelphia, Lippincott,.

2. Bauer A, Rödiger C, Greif C, Kaatz M, Elsner P. Vulvar Dermatoses - Irritant and Allergic Contact Dermatitis of the Vulva. Dermatology 2005;210(2):143-149.

3. Hoyme UB, Buehler K: Anatomy and physiology of the vulva, the vagina and the cervix; in Elsner P, Martius J (eds): Vulvovaginitis. New York, Dekker, 1993, pp 275-284.

4. Thompson IO, van der Bijl P, van Wyk CW, van Eyk AD. A comparative light- microscopic, electron-microscopic and chemical study of human vaginal and buccal epithelium. Arch Oral Biol 2001;46(12):1091-8. http://dx.doi.org/10.1016/ Sooo3- 9969(01)00082-6.

5. Elsner P, Wilhelm D, Maibach HI. Frictional properties of human forearm an vulvar skin: influence of age and correlation with transepidermal water loss and capacitance. Dermatologica 1990;181(2):8891. http://dx.doi.org/10.1159/ooo247892.

6. Britz MB, Maibach HI, Anjo DM. Human percutaneous penetration of hydrocortisone: the vulva. Arch Dermatol Res 1980;267(3):313-6. http:// dx.doi.org/10.1007/BFoo403852.

7. Guy RH, Potts RO, Francoeur ML. Skin barrier function and the mechanism(s) of percutaneous penetration. Acta Pharm Nord 1992;4(2):115.

8. Connor CJ, BS, Eppsteiner EE. Vulvar Contact Dermatitis. Proceedings in Obstetrics and Gynecology 2014;4(2):1-14.

9. Jones IS. A histological assessment of normal vulval skin. Clin Exp Dermatol. 1983;8(5):51321. http://dx.doi.org/10.1111/j.1365-2230.1983. tbo1818.x.

10. Summers PR, Hunn J. Unique dermatologic aspects of the postmenopausal vulva. Clin Obstet Gynecol 2007;50(3):745-51. http://dx.doi.org/10.1097/ GRF.obo13e318odb96ae.

11. Fischer GO. The commonest causes of symptomatic vulvar disease: a dermatologist's perspective. Australas J Dermatol 1996;37(1):12-8. http:// dx.doi.org/10.1111/j.1440- 0960.1996.tboo988.x.

12. Bauer A, Geier J, Elsner P. Allergic contact dermatitis in patients with anogenital complaints. J Reprod Med 2000;45(8):649-54.

13. Willis CM, Stephens CJ, Wilkinson JD. Epidermal damage induced by irritants in man: a light and electron microscopic study. J Invest Dermatol 1989;93(5):695-9. http://dx.doi.org/10.1111/15231747.ep12319895.

14. Bauer A. Regional contact dermatitis. In: Gebhardt M, Elsner P, Marks J, editors. Handbook of contact dermatitis. Malden, USA: Martin Dunitz Ltd.; 2000. p. 143-52.

15. De Groot AC, Beverdam EG, Ayong CT, Coenraads PJ, Nater JP. The role of contact allergy in the spectrum of adverse effects caused by cosmetics and toiletries. Contact Dermatitis 1988;19:195-201.

16. Fisher AA, Rietschel RL, Fowler JF. Fisher's contact dermatitis. 6th edition. Hamilton (ON): B C Decker; 2008.

17. Petersen LJ, Lyngholm AM, Arendt-Nielsen L. A novel model of inflammatory pain in human skin involving topical application of sodium lauryl sul- 
fate. Inflamm Res 2010;59(9):775-81. doi: 10.1007/ s00011- 010-0189-1.

18. O'Gorman SM, Torgerson RR. Allergic contact dermatitis of the vulva. Dermatitis 2013;24(2):64-72. doi: 10.1097/DER.obo13e318284da33.

19. Marren P, Wojnarowska F, Powell S. Allergic contact dermatitis and vulvar dermatoses. Br J Dermatol 1992;126(1):52-6.

20. LeSellin J, Drouet M, Bonneau JC, Sabbah A: Enquête allergologique dans les dermatoses de contact génitales. Allerg Immunol Paris 1991; 23:127128.

21. Fisher AA. Allergic reaction to feminine hygiene sprays. Arch Dermatol 1973;108:801.

22. Giroux L, Pratt MD. Contact dermatitis to incontinency pads in a (meth)acrylate allergic patient. Am J Contact Dermat 2002;13:143-145.

23. Hernandez N, Pabon LH. Dermatosis vulvares y pruebas epicutaneas de parch. Presentado como trabajo libre, congreso mundial de dermatología, Buenos Aires, 2007.

24. Braitman M. Contact dermatitis due to colored toilet tissue. AMA Arch Derm Syphilol 1952;65(6):727.

25. Braun-Falco O, Korting HC. Normal pH value of human skin. Hautarzt. 1986;37(3):126-9.

26. Tarun J, Susan J, Suria J, Susan VJ, Criton S. Evaluation of $\mathrm{pH}$ of Bathing Soaps and Shampoos for Skin and Hair Care. Indian J Dermatol 2014; 59(5): 442-444.

27. Corazza M, Lauriola MM, Zappaterra M, Bianchi A, Virgili A. Surfactants, skin cleansing protagonists. J Eur Acad Dermatol Venereol 201;24(1):1-6. doi: 10.1111/j.1468-3083.2009.03349.x

28. Lodén M, Buraczewska I, Edlund F. The irritation potential and reservoir effect of mild soaps. Contact Dermatitis 2003;49(2): 91-96.

29. Angelini G, Rigano L. Dermatite da contatto da cosmetici. In: Angelini, G, Vena, GA, eds. Dermatologia professionale ed ambientale. ISED, Brescia, Italy, 1997, 703-706.

30. Ananthapadmanabhan KP, Moore DJ, Subramanyan $\mathrm{K}$ et al. Cleansing without compromise: the impact of cleansers on the skin barrier and the technology of mild cleansing. Dermatol Ther 2004;17:16-25.

31. Kuehl BL, Fyfe KS, Shear NH. Cutaneous cleansers. Skin Therapy Lett 2003; 8(3):1-4.

32. Friedman M, Wolf R. Chemistry of soaps and detergents: various types of commercial products and their ingredients. Clin Dermatol 1996;14(1): 7-13.

33. Attwood D, Florence AT. Surfactant system. Their chemistry pharmacy and biology. London: Chapman and Hall, 1983: 1-11.

34. Effendy I, Maibach HI. Surfactants and experimental irritant contact dermatitis. Contact Dermatitis 1995;33(4): 217-225.

35. 37 Rosen MJ. Surfactants and interfacial phenomena. New York: John Wiley \& Sons,1978:1-25.

36. Berardesca E. La detersione. In: Caputo, R, Monti, M, eds. Manuale Di Dermocosmetologia Medica. Raffaello Cortina Editore, Milano, Italy. 1995: 8389.

37. Zografi G, Schott H, Swarbrick J. Interfacial phenomena. In: Gennaro AR (ed): Remington's pharmaceutical sciences. Easton: Mack, 1990: 257-272.

38. Singer MM, Tjeerdema RS. Fate and effects of the surfactant sodium dodecyl sulfate. Rev Environ Contam Toxic 1993:133:95-149.

39. Moran J, Addy M, Wase W G. Determination of mínimum inhibitory concentrations of comercial toothpastes using an agar dilution method. J Dent 1988: $16: 27-31$

40. Wade WG, Addy M. Antibacterial activity of some triclosan - containing toothpases and their ingredients. J Periodontol 1992: 63: $280-282$

41. Satar SA, Springthorpe VS, Karim Y, Loro P. Chemical desinfection of non - porous inanimate surfaces experimentally containated with four human pathogenic viruses, Epidem Inf 1989: 102: $493-505$.

42. Agner T. Noninvasive measuring methods for the investigations of irritant patch test reactios. A study of patients with hand eczema, atopic dermatitis and controls. Acta Derm Venereol Suppl (Stockh) 1992;173:1-26.

43. Scheuplein R, Ross L. Effects of surfactatns and solvents on the permability of epidermis. J Soc Cosmet Chem 1970;21:853-873.

44. LaRoche G, Eisler R, Tarzwell C M. Bioassay procedures for oil and iol dispersant toxicity evaluation. J Water Pollut Contr 1970;42:1982 - 1989.

45. Lee CH, Maibach HI. The sodium lauryl sulfate model: an overview. Contact Dermatitis 1995;33(1):1-7.

46. Löffler H, Happle R. Profile of irritant patch testing with detergents: sodium lauryl sulphate, sodium laureth sulphate and alkyl polyglucoside. Contact Dermatitis 2003;48(1):26-32.

47. Effendy I, Maibach HI. Detergent and skin irritation. Clin Dermatol 1996;14(1):15-21.

48. Willis CM, Stephens CJM, Wilkinson JD. Differential effects of structurally unrelated chemical irritants on the density of proliferating keratinocytes 
in $48 \mathrm{~h}$ patch test reactions.. J Invest Dermatol 1992;99(4):449 - 453 .

49. Willis CM, Stephens CJM, Wilkinson JD. Differential patterns of epidermal leukocyte infiltration in patch test reactions to structurally unrelated chemical irritants. J Invest Dermatol 1993;101(3):364 -370 .

50. Reynold EF(ed): Martindale. The extra Pharmacopoeia. 3oth edition. London: Pharmaceutical. 1993: 1215-1216.

51. Fisher's. Contact Dermatitis, 4th edn. Williams \& Wilkins, Baltimore, Maryland, USA, 1995: 288-291 and 349-351.

52. Pigatto PD, Bigardi AS, Cusano F. Contact dermatitis to cocamidopropylbetaine is caused by residual amines: Relevance, clinical characteristics, and review of the literature. Am J Contact Dermatitis 1995;6(1):13-16. https://doi.org/10.1016/1046199X(95)90062-4

53. Foti C, Mastrandrea V, Conserva A, Bonamonte D, Rigano L, Angelini G. Dermatite da contatto da detergenti. Ann Ital Dermatol Allergol 2003; 57: 1-7.

54. Gelmetti C, Colonna C. Dermocosmetologia Pediatrica. EDITEAM s.a.s., Febbraio, Bologna, Italy, 2005.

55. Fowler JF. Allergy to cocamide DEA. Am J Contact Dermatitis 1998;9(1):40-41.

56. Pinola A, Estlander T, Jolanki R, Tarvainen K, Kanerva L. Occupational allergic contact dermatitis due to coconut diethanolamide (cocamide DEA). Contact Dermatitis 1993;29(5):262-265.

57. Korting HC, Herzinger T, Hartinger A, Kerscher M, Angerpointner T, Maibach HI. Discrimination of the irritancy potential of surfactants in vitro by two cytotoxicity assays using normal human keratinocytes, HaCaT cells and 3T3 mouse fibroblast: correlation with in vivo data from a soap chamber assay. J Dermatol Sci 1994;7(2): 119 - 129.

58. Harvell J, Bason MM, Maibach HI. In vitro skin irritation assays: relevance to human skin. Clin Toxicol 1992;30(3):359 - 369.

59. Lang G, Spengler J. Abstracts of the XIV I.F.S.C.C. (The International Federation of Societies of Cosmetic Chemists) Congress in Barcelona 1986; Cosmetics Toiletries 1988; 103: 17.

6o. Froebe CL, Simion FA, Rhein LD, Cagan RH, Kligman A. Stratum corneum lipid removal by surfactants: relation to in vivo irritation. Dermatologica 1990;181(4): 277-283.

61. Emery B. Edwards L. The pharmacology of soaps. III. Irritant action of sodium alkyl sulphates of human skin. J Am Pharm Ass 1940;29(6): 254 - 255.
62. Bettley FR. The influence of soap on the permeability of the epidermis. Br J Dermatol 1961;73: 448 $-451$.

63. Mezei M, Sager R W, Stewart WD, De Ruyter AL. Dermatitic efectos of non - ionic surfactants. J Pharm Sci 1966;55(6): 584-589.

64. Wilhelm K P, Cua AB, Wolf HH, Maibach HI. Surfactant - induced stratum corneum hidration in vivo: prediction of the irritation potential of anionic surfactants. J Invest Dermatol 1993;101(3): $310-315$.

65. Kligman AM, Wooding WM. A method for the measurement and evaluation of irritants on human skin. J Invest Dermatol 1967;49(1): 78 - 94 .

66. Rhein LD, Simion FA. Surfactant interactions with skin. Surf Sci Ser 1991;32:33 - 49

67. Johnson AW. Overview: fundamental skin care protecting the barrier. Dermatol Ther 2004;17: 1-5.

68. Blume-Peytavi U, Lavender T, Jenerowicz D, Ryumina I, Stalder JF, Torrelo A, et al. Recommendations from a European Roundtable Meeting on Best Practice Healthy Infant Skin Care. Pediatr Dermatol. 2016 May;33(3):311-21. doi: 10.1111/ pde.12819

69. Draelos ZD. The science behind skin care: Cleansers. J Cosmet Dermatol. 2018;17(1):8-14. doi: 10.1111/jocd.12469

70. Gardner HL: Contact vulvovaginitis: Primary irritant and allergic reactions; in Gardner HL, Kaufman RH (eds): Benign Diseases of the Vulva and the Vagina, ed 2. Boston, Hall Med- ical Publishers, 1980, pp 431-432.

71. Singh A, Prieto VG, Czelusta A, McClain KL, Duvic M. Adult Langerhans cell histiocytosis limited to the skin. Dematology 2003;207(2):157-161. 